late Prof. W. A. Bone. In 1912 Dr. Hartley was appointed chief chemist to the Richmonds Gas Stove and Meter Co., where he built up a technical and research section and continued the work on the measurement of the radiant efficiency of gas fires which had been started at Leeds in 1908. In 1919 he was appointed head of the research department of Radiation, Ltd., on the formation of that company. At the new central research laboratories in Grosvenor Place, London, he directed many important investigations into the design of gas-fired appliances, including those culminating in the production of the Bennett/ Hartley integrating radiometer for determining the radiant efficiency of domestic heating appliances. He was awarded the C.B.E. in 1952.

\section{Official Seed Testing Station for England and Wales}

Mr. P. S. Wellington has been appointed chief officer of the Official Seed Testing Station for England and Wales in succession to Mr. C. C. Brett, who retired in April. Born in 1919, Mr. Wellington entered the Imperial College of Science and Technology, London, in 1937. During 1939-46 he served. in the Air Branch of the Royal Navy and was awarded the ID.S.C. On returning to the University of London after the War, he obtained a first-class honours degree in botany. He was appointed to the Official Seed Testing Station as senior assistant to the chief officer in 1947, and has been investigating the premature sprouting in the grain of wheat. The Official seed 'Testing Station is administered, on behalf of the Ministry of Agriculture and Fisheries, by the National Institute of Agricultural Botany, Cambridge.

\section{The Imperial Institute}

$I_{N}$ the House of Lords on December 9, Viscount Falmouth, directing attention to the report of the Tweedsmuir Committee on the Imperial Institute, asked whether the Government would consider the transfer of the Institute to a more suitable place and thus free the present site for expansion of the Imperial College of Science and Technology in order to provide additional facilities for the higher training of scientists and engineers. Viscount Falmouth was specially concerned with the expansion of the Imperial College ; but, while there was general agreement in the subsequent debate as to the desirability of expanding the Imperial College, other speakers were not prepared to support its claims against the Imperial Institute, and Lord Hailey asked for a specific assurance from the Government that it did not contemplate the abandonment of the present Institute building in favour of the College. Earl De La Warr, replying for the Government, declined to make any definite statement regarding the Government's future schemes for higher technological education or the Government's views on the Tweedsmuir Report. A definite statement of the Government's policy with regard to higher technological education, it was said, would be made early in the New Year. As regards the Imperial Institute, since the Institute is financed and supported by forty-nine governments in all, transfer of the Institute to another site could only occur, if at all, after discussion with the Institute and all those Dominion and Colonial governments which are partners in its maintenance. He added that, as soon as it is possible to discuss definite proposals, the Government, which already controls so much of the land adjoining the College buildings at South Kensington, will be concerned to assist the development of the Imperial College in the best way that it can; but he could not say in advance how far that may involve the Imperial Institute.

\section{Journal of the Royal Society of Arts: 1852-1952}

THE first issue of the Journal of the Royal Society of Arts was published on Friday, November 26, 1852, and to mark this event the centenary number of the Journal (101, No. 4887; 1952) briefly records its history. 'The Royal Society of Arts is, of course, nearly twice as old as its Journal, having been founded in 1754, and its activities were at first chronicled in various publications and in its annual Transactions. Dr. James Booth, F.R.S., vicar of Wandsworth, who was an ordinary member of the Society, first suggested the idea of a weekly journal in a letter addressed to the Council of the Society in 1852. In this letter he set out in considerable detail the scheme for a weekly newspaper, which should record all the Society's proceedings, serve as a medium between the Society and allied institutions and form a permanent record of the progress of science, art and industry. This project was taken up, and weekly publication was continued until March 22, 1940, since when the Journal has appeared at fortnightly intervals, still published, as was the first issue, on a Friday. The circulation almost automatically follows the membership of the Society : in 1853 it was 2,250 , and this more or less consistently increased until 1873 , when it was 4,350 ; during $1873-1932$ it dropped to $3,000-3,500$, but since then it has regularly increased to its present figure of about 6,000 members. The chief aim of the Journal has remained constant-namely, the publication of the great mass of information contained in the authoritative papers read to the Society and the often most interesting and sometimes entertaining discussions which they have provoked. There has been virtually no limit to the range of subject-matter, provided only that there is, in each individual exposition, some germ of progress, some new line of approach that tends to the advancement of human welfare. To the published papers there have been added reports of the Society's activities; illustrations in the shape of photographs, drawings, maps and diagrams; book reviews ; obituaries ; miscellaneous notes of interest ; and announcements of meetings of other societies. For a centenarian, the Journal of the Royal Society of Arts is an active old gentleman; may the second hundred years of its existence be as flourishing as the first.

\section{University of Paris: Honorary Degrees}

Ат a Séance solennelle de Rentrée in the amphitheatre of the Sorbonne held on November 29, and in the presence of the President of the French Republic and the Minister of National Education, M. le Recteur Sarrailh conferred the degree of doctor honoris causa of the University of Paris on the following: Dr. O. da Fonseca, director of the Instituto Oswaldo Cruz of Rio de Janeiro; Prof. R. F. Loeb, professor of medicine in Columbia University; Prof. M. Siegbahn, professor in the Royal Academy of Sciences of Sweden; Prof. $H$. Weyl, honorary professor in the Institute for Advanced Study in Princeton; Sir Rudolph Peters, professor of biochemistry in the University of Oxford; and Prof. A. I. Virtanen, professor of biochemistry in the Valio Institute of Helsinki. Similar degrees were also conferred upon four other persons distinguished in law and letters. 